\title{
A revisão do Código Florestal Brasileiro: impactos negativos para a conservação dos anfíbios
}

\author{
Luís Felipe Toledo ${ }^{1,6}$, Sergio Potsch de Carvalho-e-Silva ${ }^{2}$, Celso Sánchez ${ }^{3}$, \\ Marina Amado de Almeida 4 \& Célio Fernando Baptista Haddad ${ }^{5}$ \\ ${ }^{1}$ Museu de Zoologia "Prof. Adão José Cardoso", Instituto de Biologia, \\ Universidade Estadual de Campinas - UNICAMP, CP 6109, CEP 13083-863, Campinas, SP, Brasil \\ ${ }^{2}$ Departamento de Zoologia, Instituto de Biologia, Universidade Federal do Rio de Janeiro - UFRJ, \\ CP 68044, CEP 21944-970, Rio de Janeiro, RJ, Brasil \\ ${ }^{3}$ Departamento de Didática, Escola de Educação, Universidade Federal do Estado do Rio de Janeiro - UNIRIO \\ ${ }^{4}$ Rua Alves Guimarães, 1354, apt. 71, CEP 05410-002, Pinheiros, São Paulo, SP, Brasil \\ ${ }^{5}$ Departamento de Zoologia, Instituto de Biociências, Universidade Estadual Paulista - UNESP, \\ CP 199, CEP 13506-970, Rio Claro, SP, Brasil \\ ${ }^{6}$ Autor para correspondência: Luís Felipe Toledo, e-mail: toledolf2@yahoo.com
}

TOLEDO, L.F., CARVAlHO-E-SIlVA, S.P., SÁNCHEZ, C., ALMEIDA, M.A. \& HADDAD, C.F.B. The review of the Brazilian Forest Act: harmful effects on amphibian conservation. Biota Neotrop. 10(4): http://www.biotaneotropica.org.br/v10n4/en/abstract?article+bn00410042010.

\begin{abstract}
In the last months there is a growing discussion in Brazil about a new Brazilian Forest Act (Código Florestal). This new proposal, in substitution to the current Act, includes modifications which will affect negatively natural populations of amphibians. Besides the deleterious impacts upon amphibians, it will also harm the national and international human populations. Among the possible effects, in consequence of the associate amphibian population declines or complete loss, we cite the increase of agricultural production costs, loss of primary sources of compounds for the medical industry, generalized ecological disequilibrium, eutrofication of water bodies, increase in the costs of water (for humans) treatment, increase of agricultural plagues, and increase of insect borne diseases. All these effects are of high relevance, even more if we consider the population declines of amphibians, the most threatened terrestrial vertebrate group in the world. Therefore, we propose that if a new Forest Act must be prepared, that it should be based, besides in unlikely immediate economical benefits to farm owners, in scientific knowledge which benefits nature conservancy, economy, health, and human welfare.
\end{abstract}

Keywords: conservation, threats, law, amphibians, Brazil.

TOLEDO, L.F., CARVALHO-E-SILVA, S.P., SÁNCHEZ, C., ALMEIDA, M.A. \& HADDAD, C.F.B. A revisão do Código Florestal Brasileiro: impactos negativos para a conservação dos anfíbios. Biota Neotrop. 10(4): http://www.biotaneotropica.org.br/v10n4/pt/abstract?article+bn00410042010.

Resumo: Nos últimos meses está em efervescente discussão uma proposta para que um novo código florestal (Projeto de Lei $n^{\circ} 1876 / 99$ ) substitua o vigente instaurado por meio da Lei Federal $n^{\circ}$ 4771/65 e modificado recentemente por Medidas Provisórias. Este novo código proposto, todavia, propõe alterações legais que devem afetar negativamente as populações naturais de anfíbios do Brasil. O declínio de anfíbios deve gerar impactos negativos tanto para a população (humana) nacional, como para a comunidade internacional. Entre os possíveis efeitos dessa lei, em consequência da perda de diversidade de anfíbios, podemos citar o aumento nos custos de produção agrícola, perda de matéria prima para produção de remédios, descontrole ecológico, eutrofização de corpos d'água, encarecimento do custo do tratamento de água para abastecimento humano, aumento de pragas agrícolas e aumento de doenças transmitidas por insetos vetores. Isto tudo é bastante preocupante ainda mais se levarmos em conta a própria perda da biodiversidade de anfíbios, o grupo de vertebrados terrestres mais ameaçado do planeta. Sendo assim, ressaltamos a necessidade de que, caso um novo código florestal seja elaborado, este tenha embasamento também em questões técnicas e científicas que impreterivelmente afetam, não só a conservação da natureza, mas também a economia, saúde e bem estar das populações humanas.

Palavras-chave: conservação, ameaças, legislação, anfíbios, Brasil. 


\section{Introdução}

Anfíbios estão em declínio no mundo todo, provavelmente por um sinergismo de fatores (Hayes et al. 2010), o que os torna o grupo de tetrápodes (vertebrados terrestres) mais ameaçados da atualidade (Stuart et al. 2004; mas ver Pimenta et al. 2005). A taxa de declínio dos anfíbios é de no mínimo 211 vezes maior do que a predita pelo registro fóssil (McCallum 2007) e certamente a degradação ambiental causada pelo homem é o fator que mais tem incrementado as taxas de declínio e extinção destes animais. Sendo assim, Wake \& Vredenburg (2008) sugerem que estamos entrando na sexta onda de extinção em massa dos anfíbios. As cinco anteriores foram naturais e esta sexta é, provavelmente, acelerada pelos impactos causados pela sociedade (McCallum 2007). Declínios catastróficos são ainda mais preocupantes quando ocorrem nas regiões de alta riqueza e endemismo de espécies do planeta. Este é justamente o caso do Brasil, detentor absoluto do maior número de espécies, abrigando aproximadamente $17 \%$ da diversidade global, e o maior número de espécies endêmicas do mundo (Frost 2010, SBH 2010). Esta riqueza ainda está em constante ascensão e deve aumentar significativamente nos próximos anos, por meio de descrições de novas espécies e rearranjos taxonômicos (e.g., Araújo et al. 2009).

Dentre as diversas causas de declínio dos anfíbios, a principal provavelmente é a perda de hábitats (Stuart et al. 2004, Toledo 2009). Sendo assim, os países devem preservar ao máximo as áreas de vegetação nativa para conservação da fauna associada. Com isto em mente, nos voltamos ao Código Florestal Brasileiro, cunhado em 1965 (Lei Federal no 4.771, 15 de setembro de 1965) e desde então alterado diversas vezes por variados instrumentos legais (e.g., Lei Federal no 7.803/89, Medida Provisória no 1956-50/00, Medida Provisória $\left.n^{\circ} 2.166-67 / 01\right)$. Este é considerado um dos melhores códigos de proteção ambiental governamental do mundo, incorporando percepções bastante avançadas para a época e que se perseveram na atualidade.

No entanto, uma parcela de políticos e da população brasileira indica a necessidade de revisão e atualização deste código em prol da economia e da sustentabilidade. Então, um novo código está sendo proposto e já tramita em instâncias governamentais com possível aprovação (Projeto de Lei $n^{\circ} 1.876 / 99$ ). Entretanto, as alterações propostas para o código pecam em diversos aspectos conceituais e práticos, colocando em risco a conservação dos anfíbios e da biodiversidade em geral (Metzger et al. 2010, Michalski et al. 2010). Sendo assim, constituem uma grande ameaça à conservação e caminha em direção oposta às diretrizes e compromissos assumidos pelo estado brasileiro em tratados e convenções nacionais e internacionais no campo ambiental, como a Declaração do Rio sobre Meio Ambiente e Desenvolvimento (Rio 92 ou Eco 92) e a Convenção sobre Diversidade Biológica (CDB), entre outros. Esta mesma previsão está sendo feita para outros grupos da fauna e flora do Brasil pela comunidade científica (ver outros artigos deste número), nos estimulando à produção do presente artigo, que deve compor um compêndio de informações que virá a contribuir para a formulação de um código florestal sustentado sobre bases científicas.

\section{Métodos}

Nós examinamos o código florestal vigente (Lei Federal $\mathrm{n}^{\circ} 4.771 / 65$ e alterações subsequentes) e a nova proposta (Projeto de Lei $\left.n^{\circ} 1.876 / 99\right)$. Assim, elencamos algumas das possíveis alterações que poderiam afetar a conservação de anfíbios no Brasil. Ademais, reunimos informação sobre o número de espécies de anfíbios da Mata Atlântica que habita riachos e qual o tamanho (em largura) dos riachos que estas espécies ocupam.

\section{Resultados e Discussão}

Identificamos algumas alterações do substitutivo aprovado pela comissão especial da câmara dos deputados que devem ser as principais à luz da conservação de anfíbios em território nacional. Estas estão listadas e comentadas a seguir:

- Anistia geral aos proprietários que desrespeitaram os limites legais em termos das Reservas Legais e/ou das Áreas de Preservação Permanente.

- Medidas como esta incentivarão o desmatamento, gerando as principais causas de declínios de anfíbios no mundo: redução e fragmentação de hábitat (Stuart et al. 2004, Becker et al. 2007). Estas ações levam também a consequências derivadas, como endogamia (perda de diversidade genética e todos seus efeitos associados) por causa do isolamento (Dixo et al. 2009), perda de microhábitats (inviabilizando a permanência de espécies especializadas, como aquelas que vivem em bromélias; e.g., Haddad et al. 2008), aumento da radiação UV-B pela insolação direta sobre ovos, larvas e pós-metamórficos e aquecimento global, sendo este com múltiplas consequências para os anfíbios, como aumento da letalidade de doenças pré-existentes, redução do tempo de corpos d'água temporários e mortalidade dos ovos e larvas, etc. (Pounds 2001, Pounds et al. 2006, Hayes et al. 2010). Ressaltamos aqui que o aquecimento global, não só afeta a fauna do Brasil, como a de todo o planeta.

- Ademais, a nova legislação poderia criar precedentes legislativos que possibilitariam estados e municípios a reverem suas legislações de proteção ambiental em consonância com o novo código, podendo criar um efeito em cascata aumentando o risco e a vulnerabilidade de conservação da biodiversidade.

- Redução da área da Reserva Legal no Cerrado de 50 para $20 \%$.

- Redução da área de Reserva Legal da Amazônia de 80 para $50 \%$.

- Não existe indicação de que as espécies de anfíbios necessitem de menos área preservada no Cerrado quando em comparação com a Amazônia ou qualquer outro Bioma. Portanto, sob a ótica de conservação dos anfíbios, não há evidência de que as áreas de RL devam ser distintas entre os biomas. Estudos regionais devem determinar qual a faixa ideal para cada grupo taxonômico e deve-se basear as medidas pelo grupo mais restritivo (i.e., que necessita de maior área). De qualquer maneira, estas proposições implicam em redução de hábitat que, como já dito anteriormente, é a principal causa de declínio de anfíbios.

- Redução, de 30 para 15 m, das áreas de APP que margeiam cursos d'água com largura inferior a $5 \mathrm{~m}$.

- O número de espécies de anfíbios que ocupam riachos (para reprodução e, consequentemente, sobrevivência) é inversamente proporcional à largura do riacho (Figura 1). Tendo como base os anuros da mata atlântica que reproduzem exclusivamente em riachos de interior de mata ( $n=136$ espécies), notamos que $100 \%$ das espécies habitam riachos menores do que $5 \mathrm{~m}$ de largura, cerca de 7,5\% das espécies $(n=10)$ podem também ocorrer em riachos de até $10 \mathrm{~m}$ de largura, e apenas uma espécie pode ocorrer em riachos entre 10 e $20 \mathrm{~m}$ de largura. Nenhuma espécie é registrada em riachos ou rios maiores. Sendo assim, a faixa prioritária para conservação de anfíbios é justamente a de menor proteção segundo o código (Figura 1). Além disso, embora os anfíbios se reproduzam no riacho propriamente 


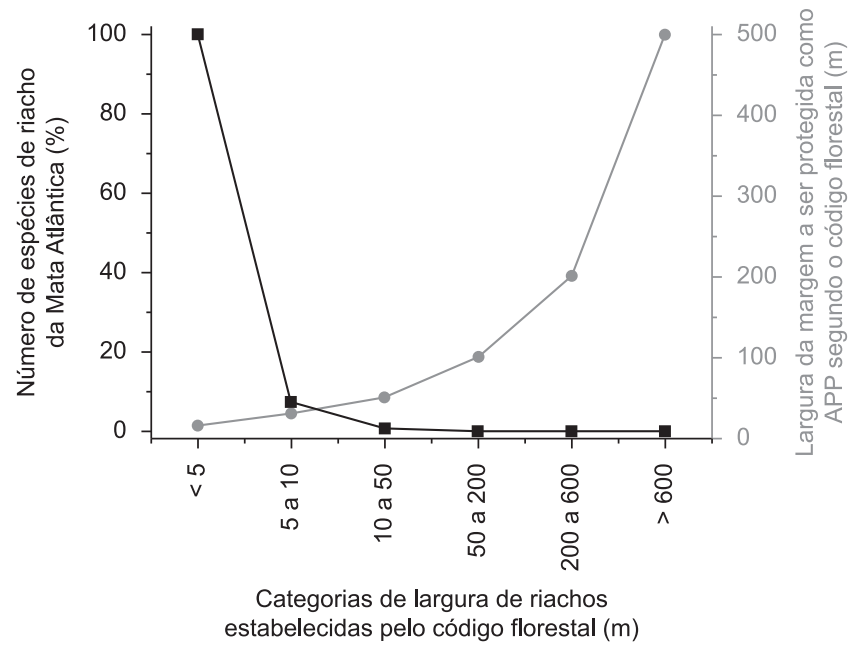

Figura 1. Número de espécies que reproduzem exclusivamente em riachos de áreas florestadas da mata Atlântica (quadrados e linhas pretas, eixo da esquerda) e largura da Área de Proteção Permanente (APP: círculos e linhas cinza, eixo da direita) para cada faixa de largura de riacho. O código atual considera a faixa de APP de $30 \mathrm{~m}$ para riachos até $10 \mathrm{~m}$ de largura e o novo código propõe a distinção dos riachos de menos de $5 \mathrm{~m}$ com APPs de $15 \mathrm{~m}$. Em raríssimas ocasiões alguns indivíduos de algumas espécies de anuros se reproduzem em rios com mais de $20 \mathrm{~m}$ de largura.

Figure 1. Number of species that reproduces exclusively in streams inside forested areas within the Atlantic forest (black squares and lines, left axis) and Permanent Protected Areas (APP: gray circles and lines, right axis) for each stream width. The current Forest Act indicates that APPs must have at least $30 \mathrm{~m}$ of width for streams up to $10 \mathrm{~m}$ width; the new proposal indicates that for streams with less than $15 \mathrm{~m}$ of width the APP must be of $15 \mathrm{~m}$ width Some anuran species rarely reproduce in streams larger than $20 \mathrm{~m}$ width.

dito, muitas espécies utilizam as matas ciliares como abrigo e sítio de alimentação. Desta forma, é certo que esta redução de metragem causará declínios populacionais e eventualmente extinções de espécies reofílicas (que vivem em riachos) de anfíbios. Ademais, existem ainda aquelas espécies que vivem na zona de várzea e que também serão fortemente afetadas.

- Alteração da demarcação da faixa de APP às margens de corpos d'água para o leito menor (nas secas) e não o maior (nas cheias)

- Além de inúmeras espécies de anfíbios que reproduzem diretamente em riachos, existem aquelas que utilizam lagoas temporárias no interior de matas, surgidas na época das chuvas e muitas vezes na região de várzea dos riachos (justamente por se tratar de uma região de várzea). Desta maneira, a destruição destes ambientes, deve acarretar em declínio de espécies terrestres ou aquelas adaptadas a reprodução em corpos de água temporários. Mais uma vez, muitas espécies podem apresentar declínios populacionais caso esta medida seja incorporada ao código florestal.

- Locais com altitudes superiores a 1800 m também deixarão de ser considerados APP.

- Topos de morros, montes, montanhas e serras deixarão de ser considerados APP.

- É de conhecimento científico que áreas de elevada altitude, bem como serras e topos de morros, são regiões de alto endemismo para anfíbios no mundo e também no Brasil, seja por condições climáticas específicas ou por questões relativas a barreiras geográficas (Cruz \& Feio 2007). Sendo assim, a perda de proteção nesta quota altitudinal acarretará em impacto negativo sem precedentes aos anfíbios: muitas espécies, ou mesmo gêneros inteiros, deverão ser extintos, já que não possuem populações em regiões de mais baixa altitude.

- Permite revegetação com espécies exóticas em áreas de Reserva Legal.

- Muitas espécies dependem de plantas específicas. Por exemplo, algumas espécies depositam seus ovos especificamente em bromélias (e.g., Scinax spp., Dendrophryniscus spp., Phyllodytes spp.), outras em ocos de árvores (e.g., Trachycephalus spp. e Osteocephalus spp.), ou de bambus (Flectonotus spp.) e algumas (e.g., Phyllomedusa spp., Hyalinobatrachium spp., Dendropsophus spp. e Vitreorana spp.) depositam ovos em folhas às margens de corpos d'água que devem ter um tamanho e maleabilidade adequados. Portanto, o uso de espécies exóticas na revegetação de áreas de Reserva Legal poderá impactar negativamente a reprodução de espécies de anfíbios com estas características.

- Ademais, mesmo que feita com espécies nativas, a revegetação não implica necessariamente na reposição total da comunidade de fauna, criando um ecossistema incompleto que não necessariamente assegura a permanência e sobrevivência de anfíbios. O ideal, em projetos de recuperação ambiental é que se busque recompor a vegetação o mais próximo possível da condição original, na tentativa de se restaurar o ecossistema.

- Permite compensação (recomposição de matas) em áreas do mesmo bioma, mesmo que distantes.

- Esta proposição ignora por completo a biogeografia de espécies de anfíbios neotropicais. Anfíbios encontrados ao Norte da Mata Atlântica não são os mesmos encontrados ao sul; as espécies do Leste da Amazônia não são as mesmas que ocorrem no oeste amazônico; e assim por diante. Neste contexto, esta proposta não é justificável e acarretará em perdas de espécies nas áreas desmatadas.

\section{O que implicaria a perda dos anfíbios?}

Além de interesses puramente científicos, a perda de diversidade de anfíbios pode acarretar em muitos danos para a população brasileira e mundial, dentre os quais destacamos:

- Prejuízos quantitativos e qualitativos na agricultura e poluição ambiental.

- Anfíbios se alimentam fundamentalmente de insetos e consomem uma quantidade massiva destes organismos por ano. A remoção dos anfíbios em um ambiente deve, portanto, acarretar em desequilíbrio ecológico, gerando surtos de pragas agrícolas. Esta situação já foi registrada na Índia, gerando necessidade de uso extensivo de inseticidas, causando prejuízos ao agronegócio e aumentando a poluição ambiental (Oza 1990). Um grande número de pessoas vem buscando cada vez mais produtos orgânicos que só podem ser produzidos com auxílio de controle biológico feito pelos predadores como os anfíbios.

- Eutrofização de corpos d'água.

- Uma boa parcela dos girinos (fase larval dos anfíbios) se alimenta de algas e a extirpação destas larvas dos ambientes aquáticos pode levar à eutrofização de rios e principalmente de reservatórios de água. Isto pode prejudicar o abastecimento de água potável para a população, além de encarecer o valor do seu tratamento para o consumo humano. 
- Desequilíbrio de redes tróficas.

- Anfíbios muitas vezes correspondem à maior biomassa de vertebrados terrestres em um ambiente e constituem a base da dieta de diversos organismos terrestres e aquáticos. Ademais, se alimentam de uma grande quantidade de invertebrados, proporcionando seu controle. Logo, a extinção ou declínio dos anfíbios de um ambiente deverá acarretar desequilíbrios em diversos níveis tróficos, prejudicando o ecossistema como um todo. Um dos possíveis efeitos é o aumento de epidemias de doenças transmitidas por insetos vetores (Raghavendra et al. 2008), tais como dengue, malária, febre amarela, dentre inúmeras outras.

- Indústria farmacêutica afetada.

- Anfíbios produzem uma miríade de substâncias por suas glândulas cutâneas, para defesa contra predadores, contra microorganismos e patógenos, ou mesmo para permitir trocas gasosas adequadas (já que boa parte da respiração é cutânea). Muitos destes compostos químicos estão sendo utilizados para produção de fármacos no Brasil e no mundo (Camargo 2005, Pukala et al. 2006). Sendo assim, a perda de biodiversidade de anfíbios implica diretamente na perda de inúmeros fármacos potenciais para benefício da humanidade.

\section{Conclusões}

Por fim, concluímos que a nova proposta para o código florestal: i) promoverá perda de biodiversidade na região com maior riqueza de espécies do planeta; ii) ignora princípios básicos da biologia da conservação (como a biogeografia, teoria de redes tróficas e estudos de impacto ambiental); iii) causará prejuízos à economia, saneamento básico, saúde pública, reduzindo a qualidade de vida da população; iv) poderão ser abertos precedentes para legislações estaduais e municipais que coloquem ainda mais em risco a preservação e a conservação da natureza; e v) terá efeitos prejudiciais não só restritos ao Brasil, mas que também impactarão comunidades internacionais (e.g., aquecimento global e produção de fármacos).

Acreditamos que as propostas de alteração do código florestal devam ser revistas, para que estejam em consonância com os princípios do estado de direito ambiental assegurados pelos compromissos já firmados no país e pela Constituição Federal. Salienta-se ainda que esse processo deva ser feito com participação de membros da comunidade científica para que realmente atinja seu objetivo primário: a conservação dos recursos naturais do Brasil.

\section{Agradecimentos}

Carlos Alfredo Joly revisou versões preliminares do artigo. FAPESP concedeu financiamento (proc. no. 2008/50325-5) e uma bolsa de estudos (proc. no. 2008/52847-9) para LFT. FAPESP e $\mathrm{CNPq}$ concederam suporte financeiro para CFBH. FAPERJ concedeu financiamento para SPCS.

\section{Referências Bibliográficas}

ARAÚJO, O.G.S., TOLEDO, L.F., GARCIA, P.C.A. \& HADDAD, C.F.B. 2009. Lista de anfíbios do Estado de São Paulo. Biota Neotrop. 9(4):1-13.

BECKER, C.G., FONSECA, C.R., HADDAD, C.F.B., BATISTA, R.F. \& PRADO, P.I. 2007. Habitat Split and the Global Decline of Amphibians. Science 318:1775-1777.
CAMARGO, A.C.M. 2005. Perspective for pharmaceutical innovation in Brazil - Center for Applied Toxinology (CEPID- Center for Research, Innovation and Dissemination - FAPESP). J. Venom. Anim. Toxins incl. Trop. Dis. 11(4):384-390.

CRUZ, C.A.G. \& FEIO, R.N. 2007. Endemismos em anfíbios em áreas de altitude na Mata Atlântica no sudeste do Brasil. In Herpetologia no Brasil II (L.B. Nascimento \& M.E. Oliveira, ed.). Sociedade Brasileira de Herpetologia, Belo Horizonte, p.117-126.

DIXO, M., METZGER J.P., MORGANTE, J.S. \& ZAMUDIO, K.R. 2009. Habitat fragmentation reduces genetic diversity and connectivity among toad populations in the Brazilian Atlantic Coastal Forest. Biol. Cons. 142:1560-1569.

FROST, D.R. 2010. Amphibian Species of the world: an online reference. Version 5. 4. American Museum of Natural History, New York, USA. http://research.amnh.org/vz/herpetology/amphibia/.

HADDAD, C.F.B., TOLEDO, L.F. \& PRADO, C.P.A. 2008. Atlantic Forest Amphibians. Editora Neotropica, São Paulo.

HAYES, T.B., FALSO, P., GALLIPEAU, S. \& STICE, M. 2010. The cause of global amphibian declines: a developmental endocrinologist's Perspective. J. Exp. Biol. 213:921-933.

McCALLUM, M. 2007. Amphibian decline or extinction? Current declines dwarf background extinction rate. J. Herpetol. 41(3):483-491.

METZGER, J.P., LEWINSOHN, T.M., JOLY, C.A., VERDADE, L.M., MARTINELLI, L.A. \& RODRIGUES, R.R. 2010. Brazilian law: full speed in reverse? Science 329:276-277.

MICHALSKI, F., NORRIS, D., PERES, C.A. 2010. No return from biodiversity loss. Science 329:1282.

OZA, G.M. 1990. Ecological effects of the frog's legs trade. Environmentalist 10(1):39-42.

PIMENTA, B.V.S., HADDAD, C.F.B., NASCIMENTO, L.B., CRUZ, C.A.G. \& POMBAL Jr., J.P. 2005. Comment on "status and trends of amphibian declines and extinctions worldwide". Science 309(5743).

POUNDS, J.A. 2001. Climate and amphibian declines. Nature 410:639-950.

POUNDS, J.A., BUSTAMANTE, M.R., COLOMA, L.A., CONSUEGRA, J.A., FOGDEN, M.P.L., FOSTER, P.N., LA MARCA, E., MASTERS, K.L., MERINO-VITERI, A., PUSCHENDORF, R., RON, S.R., SÁNCHEZ-AZOFEIFA, G.A., STILL, C.J. \& YOUNG, B.E. 2006. Widespread amphibian extinctions from epidemic disease driven by global warming. Nature 439:161-167.

PUKALA, T.L., BOWIE, J.H., MASELLI, V.M., MUSGRAVE, I.F. \& TYLER, M.J. 2006. Host-defense peptides from the glandular secretions of amphibians: structure and activity. Nat. Prod. Rep. 23:368-393.

RAGHAVENDRA, K., SHARMA, P. \& DASH, A.P. 2008. Biological control of mosquito populations through frogs: opportunities \& constrains. Indian J. Med. Res. 128:22-25.

SOCIEDADE BRASILEIRA DE HERPETOLOGIA - SBH. 2010. Brazilian amphibians - List of species. http://www.sbherpetologia.org.br (ultimo acesso em 1/07/2010).

STUART, S.N., CHANSON, J.S., COX, N.A., YOUNG, B.E., RODRIGUES, A.S.L., FISCHMAN, D.L. \& WALLER, R.W. 2004. Status and trends of amphibian declines and extinctions worldwide. Science 306:1783-1786.

TOLEDO, L.F. 2009. Anfíbios como bioindicadores. In: Bioindicadores da qualidade ambiental (S. Neumann-Leitão \& S. El-Dier, org.). Instituto Brasileiro Pró-Cidadania, Recife, p.196-208.

WAKE, D.B. \& VREDENBURG, V.T. 2008. Are we in the midst of the sixth mass extinction? A view from the world of amphibians. PNAS 105(1):11466-11473. 